\title{
Instant Messaging Reference in an Academic Library: A Case Study
}

\section{Marianne Foley}

\begin{abstract}
Most academic libraries offer some form of digital reference service through e-mail or Web forms. Now many libraries are moving toward an almost-immediate form of digital reference: instant messaging. During the 2000-2001 academic year, the General Libraries of the University at Buffalo conducted a pilot project to assess the feasibility of providing reference through instant messaging. The libraries used the popular "chat room" format and America Online's Instant Messenger software. This article describes the project, its implementation, the software used, staffing issues, and publicity efforts. It also discusses the results of the project in terms of user demographics, satisfaction levels, usage statistics, patron comments, and librarian feedback. Finally, the article offers conclusions about offering instant messaging reference in a large academic library.
\end{abstract}

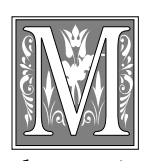

ost academic libraries offer some form of digital reference service. Digital reference, also known as online reference, electronic reference, and e-reference, uses the Internet to allow librarians to communicate online with users beyond library walls. E-mail and Web forms have become the most common forms of digital reference, but these impersonal methods involve some time delay. Many libraries now are turning to an almost-immediate, slightly more sophisticated form of digital reference: instant messaging. ${ }^{1}$ The General Libraries of the University at Buffalo (UB) conducted a pilot project in instant messaging reference service during the 2000-2001 academic year. The libraries used the popular "chat room" format and America Online's Instant Messenger software. Throughout the project, user demographic and satisfac- tion statistics, user comments, and usage data were collected. When the pilot concluded, this information was reviewed together with librarian input, software performance, staffing issues, and publicity to determine the viability of providing instant messaging reference on a regular basis. This article describes the project, its implementation, the software used, staffing issues, and publicity efforts. It also discusses the results of the project and gives conclusions.

\section{What Is Instant Messaging?}

Instant messaging (IM) has become a popular communication method, especially among younger people who form a large segment of the libraries' patron population. Simply stated, IM is real-time online communication between two or more people. The medium enables people to "chat" via the Internet by rapidly ex- 
changing text messages. One user chats with another user by typing a message into a specialized window, or "chat room," generated by IM software. The message appears almost immediately on the other user's screen. The recipient reads it and replies by typing a response. Only an Internet connection is required to access basic chat systems. Typically, the IM system emits sounds when a person transmits or receives a message. Several people can chat at one time because all users see messages that appear in the chat room. Those who want to chat privately create a private chat room where only invited users may participate.

Some IM products allow users to send images and video, play games, exchange files, and synchronize Web browsing. Computers equipped with microphones enable users to chat in the literal (verbal) sense, although system hardware and connection restraints can introduce annoying breaks in transmission. A growing number of companies produce IM software, and although these competing products function in a similar way, no software standard currently exists. Furthermore, company mergers and acquisitions are common. A system that is here today may be gone tomorrow; free products mutate to fee-based services.

IM presents an alternative for librarians seeking to reshape the delivery of reference services. ${ }^{2}$ Because physical boundaries do not stand in the way of communication, it is possible to reach remote users across campus and around the world. In addition to immediacy, convenience, and accessibility, online reference offers other advantages. Patrons who are embarrassed by the nature of their question or their lack of knowledge can remain anonymous during IM reference. Interactive text communication accommodates multiple learning styles, the hearing impaired, and people who are not native English speakers. Complicated URLs that prove difficult to communicate correctly over the phone, and even at the reference desk, can be easily transferred during online reference. ${ }^{3}$ Unlike e-mail and Web forms, IM is well suited to conducting reference interviews, clarifying questions, and receiving feedback. ${ }^{4}$ Furthermore, it now makes telecommuting a practical alternative for busy reference librarians. However, IM reference is not a panacea. Visually impaired users and people who have trouble typing quickly will prefer other methods. ${ }^{5}$ Lengthy, complicated explanations can become unwieldy, and sometimes there simply is no replacement for face-to-face communication with a reference librarian.

\section{Project Background}

UB is the largest and most comprehensive campus in the State University of New York system, with approximately 25,000 undergraduate, graduate, and professional-degree students. The administration requires all freshmen to have access to a computer running Windows 98, NT or higher, or the Apple OS 9.0 operating system. Every room in student housing is wired with Ethernet ports, and public computer labs offer around-the-clock access to 2,000 high-performance workstations. The university also provides more than a thousand high-speed modems to give students, faculty, and staff access to the Internet from home. In April 2000, Yahoo! Internet Life named UB eleventh of the one hundred "Most Wired Universities." 6

The UB Libraries Web site, BISON (Buffalo Information System ONline), offers online access to myriad resources including the library catalog, journals, e-books, research guides, course reserves, and tutorials. As a result of the university's emphasis on electronic resources, the General Libraries launched an IM reference service during the fall 2000 semester. The General Libraries consist of Lockwood Memorial Library (for humanities and the social sciences), the Science and Engineering Library, and the Oscar A. Silverman Undergraduate Library.

Specifically, the General Libraries desired to:

- provide reference assistance to remote modem users without second phone lines; 
- enable distance education students to avoid long-distance phone charges;

- assist students in crowded cybraries (library computer labs) who do not want to relinquish their seats to visit a reference desk;

- make reference service more inviting to young people and others who regularly engage in real-time chat;

- provide extended reference hours.

\section{Implementation}

To choose an IM product, the General Libraries reviewed more than ten chat software programs in early 2000. Many features were considered, including (but not limited to) price, ease of use, privacy, platforms, Web browser integration, file transfers, document sharing, and spam protection. Based on this evaluation, AOL's free and ubiquitous Instant Messenger software was chosen.

AOL offers two chat alternatives: Users can download and install Instant Messenger (AIM) client software on their own computer or use the Web-based AIM Express (Express), which requires no download, only a Web browser with Java enabled. IM librarians and patrons were allowed to choose their preferred method. Both options require users to create an AOL account and then register a unique screen name and password. For consistency, one person created all librarian accounts, passwords, and user names (UBLibrarian1, UBLibrarian2, etc.).

Before launching the service, a schedule was established, shifts assigned, and library personnel notified of the start date. On October 23, 2000, the project went live with the addition of an Instant Message hyperlink to top-level BISON Web pages and an eager librarian monitoring the IM chat room. By clicking on the hyperlink, visitors were directed to the Instant Message page and given the option to download and install AIM software or to use Express. The page also described the service, provided brief instructions, and listed hours of operation. Furthermore, users were cautioned that IM service was intended to provide short answers; users with in-depth questions were advised to call, e-mail, or visit the library.

The library's computer system routed those who chose AIM directly to a chat room named ublib; patrons who selected Express had to invite themselves into $u b l i b$. After a visitor entered the $u b l i b$ chat room, the librarian on duty would take the user (by clicking on the user's screen name) to a private chat session to maintain privacy. To protect patron privacy, librarians did not maintain transcripts of the sessions.

After seven weeks of service, the fall portion of the pilot concluded on December 8,2000 , for the holiday intercession. Before the spring semester began, library administrators assessed fall statistics, staffing issues, patron comments, and librarian input. Due to encouraging statistics and positive feedback, the General Libraries decided to extend IM reference through the spring semester. In both semesters, the service ended before reading days and final exams.

\section{Software}

AOL software was found to have both advantages and disadvantages in delivering real-time reference service in a large academic library. On the positive side, AOL offers free software along with name recognition and a system that is relatively easy to learn. The chat room format accommodates multiple users and allows librarians to overlap during shift transitions. However, the staff had no control over AOL service and occasionally experienced periods of instability when they could not log in or were inexplicably disconnected during a session. Infrequently, the entire system was unavailable, which meant that IM reference service had to be canceled temporarily. When this occurred, an explanation was posted with an apology on the Instant Message Web page. Sometimes access could be gained through AIM, but not through Express, and vice versa. Occasionally, AIM users could not chat privately with Express users, possibly because of "net split," an Internet failure that interrupts communi- 
cation among groups of servers, but not within the group. ${ }^{7}$ Unlike other products, AOL chat software does not compile statistics or send automated messages to inform visitors when the librarian is busy or the service is closed.

Still, AIM has several helpful features, including the ability to easily send images, colorful emoticons, and hyperlinks. The system also emits audible signals when someone on a buddy list (a personal list of friends with AIM screen names) enters the chat room so that the librarian does not have to watch the screen continuously. Regrettably, this sound feature proved useless because librarians could not add all possible patron screen names to their buddy lists. Thus, a librarian on IM duty who chose to use AIM had to monitor the chat room vigilantly. In contrast, Express generates sounds when any visitor enters the chat room, thereby allowing the librarian on duty to perform other tasks while waiting for questions. But Express lacks the other useful features of AIM described above.

\section{Administration Issues \\ Staffing}

During the fall semester, twenty librarians and four library school students agreed to participate in the IM reference pilot project. Librarians contributed between two and seven hours per week to monitoring the IM chat room, and library students covered the evening and weekend shifts. Only one person monitored the room at a time. The library provided IM reference service an average of sixty-eight hours per week according to the following schedule: 9 a.m. until 9 p.m. Mondays, 9 a.m. until 11 p.m. Tuesdays, 9 a.m. until 8 p.m. Wednesdays and Thursdays, 9 a.m. until 6 p.m. Fridays, 1 p.m. until 3 p.m. Saturdays, and 2 p.m. until 11 p.m. most Sundays. [Note: For brevity, henceforth, this article will refer to both IM librarians and library students as librarians unless a distinction is required.]

Evaluation of IM service in the fall revealed two specific staffing challenges that needed to be addressed in the spring.
First, one person could not simultaneously staff the IM chat room and a physical reference desk because of the many distractions around a reference desk. Because AOL chat software does not provide a way to notify incoming patrons that the librarian on duty is temporarily preoccupied, an online patron could feel ignored or erroneously conclude that the system had disconnected. As a result, librarians performed their IM shifts separately from their reference desk duty in the spring.

Second, IM evening and weekend hours did not meet patron demand. To offer more hours, it was necessary to increase the size of the IM staff. Therefore, library administration requested that all reference librarians contribute one hour per week to IM reference. The IM coordinator also recruited more library students to give a total of thirty-eight IM staffers. The larger staff made it possible to offer chat reference an average of seventy-five hours per week with more evening and weekend hours. It also allowed librarians to reduce their IM shifts to one hour per week, while library students took night and weekend shifts of up to five hours.

Because only one question was received before 10 a.m. in the fall, it was decided to open one hour later in the spring. The IM chat room was staffed between 10 a.m. and 11 p.m. Monday through Thursday, 10 a.m. and 5 p.m. Friday, 11 a.m. and 5 p.m. Saturday, and 1 p.m. and 11 p.m. Sunday.

\section{Training}

Before starting the pilot project, a few tutorial sessions were conducted for librarians but were poorly attended, possibly because most of the librarians who participated in the fall were sufficiently familiar with technology or the concept of online chatting to learn it on their own. Senior librarians trained and mentored the library school students. Librarians who joined the project in the spring sought guidance from, and practiced with, veteran IM librarians. 
In terms of policy, two guidelines were established. First, IM librarians were directed to use only the $u b l i b$ chat room to minimize visitor confusion. Second, librarians who provided simultaneous reference service via IM and the physical desk were advised to give preference to patrons within the library. IM staff were encouraged to welcome visitors with a short greeting, keep their responses brief, and periodically send delay messages such as "I'm still working on it." They also were advised to refer difficult questions to a subject specialist or to encourage the patron to call or visit the library. Otherwise, the IM librarians were free to use their best judgment.

As an additional aid, a Quick Links Web page was maintained with links to ready-reference sources such as contact information for the various UB Libraries, class assignments, and frequently used BISON pages. This page was designed to allow librarians to easily copy and paste information into messages. However, IM librarians confessed to rarely using it.

\section{Librarian Communication}

Initially, everyone communicated informally through individual e-mails or small meetings, but just before launching the service, a listserv devoted to the project was created. The list was used to post weekly statistical summaries and to make announcements. Unfortunately, it did not adequately facilitate "shift trades" in the fall, so in the spring IM staff were directed to report schedule conflicts to the IM coordinator who then would arrange changes. One face-to-face meeting was held each semester to compare notes, ask questions, and make recommendations.

\section{Publicity}

Overall, IM reference service received little promotion aside from the addition of the Instant Message hyperlink throughout BISON. The IM coordinator chose not to advertise in the fall because of the project's experimental nature. It also was decided not to promote the service in bibliographic instruction sessions to prevent students from sending in a flood of course-specific questions. During the spring, publicity was delayed to give new IM staff time to become comfortable with this mode of reference interaction, although in February an article appeared in a library newsletter to describe the service. Throughout March, three advertisements were placed in the student newspaper and flyers were distributed across campus during two days in April.

\section{Data Collection \\ Patron Survey}

Demographic and satisfaction data were collected from patrons through an online questionnaire. After a patron clicked on the IM link, a separate browser window opened to display the survey. Users were asked to indicate age range, gender, the location from which they sent their message, whether they were affiliated with UB, and their degree of satisfaction with IM reference. They also were asked to briefly explain why they chose to send an instant message instead of visiting, calling, or e-mailing a library. Once complete, users transmitted the information by clicking a button labeled submit. To encourage responses, participants were offered the chance to win a $\$ 25$ gift certificate from Media Play, a large entertainment store near campus.

\section{Librarian Reports}

To ensure patron privacy, it was decided not to generate session transcripts. Still, in order to understand the nature of questions posed during IM reference, IM staff were asked to paraphrase the questions they received and to enter the information into an online form immediately after the exchange. Unfortunately, a few people completely forgot this task or submitted the question much later with some acknowledged loss in accuracy.

\section{Usage}

When a user submitted a survey, the Unix system server recorded the data along with the time and date of submission. This information was used to gauge when 
and how often the service was used. To reduce errors, a JavaScript program deleted duplicate entries (possibly caused by a user pressing submit twice) and incomplete surveys. A survey was considered complete if it contained satisfaction data and the location of the patron during the exchange. Because many people resist supplying age and gender for personal reasons, it was felt that this should not eliminate other valuable information.

To determine whether usage trends existed, the hours, days, and weeks were reviewed when surveys were submitted.

Unfortunately, this counting method cannot produce a true reflection of use because it is based on when surveys were submitted and not the actual time that a reference interview occurred. Thus, a user might ask a question in the afternoon but not submit the survey until the evening. Also, no information is available about users who did not complete the survey. Their demographics and satisfaction levels may differ greatly from those who responded.

\section{Project Findings}

Patron Demographics and Satisfaction

Demographic and satisfaction statistics were assessed for fall, spring, and both semesters combined. Because there was little to no difference between the semesters, the following values are presented for the entire pilot project. The nonresponse rate varied between 1 and 11 percent and the sample size $n$ differed for each characteristic because not all patrons completed every survey question. Table 1 summarizes the results for age, the location from which the visitor sent the message, and satisfaction level. Results worth noting include:

- The majority $(70 \%)$ of respondents were between the ages of eighteen and twenty-five.

- More users (69\%) sent their question from on-campus than from off-campus.

- Of the on-campus patrons, most $(25 \%)$ sent their message from a cybrary.

- There were no significant differences in use by gender.

- Eighty-four percent of the respondents were affiliated with UB as students, faculty, staff, or alumni.

As for satisfaction level, 45 percent of respondents reported being very satisfied with the service. In fact, 79 percent declared themselves satisfied or better compared to 10 percent who registered some level of dissatisfaction. Most of the unhappy patrons had tried to access the service when it was closed.

\section{Nature of Questions}

As mentioned earlier, librarians paraphrased the questions they received dur-

\begin{tabular}{|c|c|c|c|c|c|}
\hline \multicolumn{6}{|c|}{$\begin{array}{c}\text { TABLE } 1 \\
\text { Patron Demographics and Satisfaction Levels } \\
\end{array}$} \\
\hline $\begin{array}{l}\text { Age } \\
(n=271)\end{array}$ & $\%$ & $\begin{array}{l}\text { Message sent from ... } \\
(\mathrm{n}=272)\end{array}$ & $\%$ & $\begin{array}{l}\text { Satisfaction Level } \\
(\mathrm{n}=262)\end{array}$ & $\%$ \\
\hline$<18$ & 3 & Off campus & 31 & Very satisfied & 45 \\
\hline $18-25$ & 70 & On campus & 69 & Moderately satisfied & 8 \\
\hline $26-30$ & 6 & *Cybrary & $* 25$ & Satisfied & 26 \\
\hline $31-40$ & 4 & *Housing & $* 18$ & Somewhat dissatisfied & 4 \\
\hline $41-50$ & 8 & ${ }^{*}$ Computer lab & $* 13$ & Very dissatisfied & 6 \\
\hline $51-60$ & 4 & *Office & $* 13$ & No response & 11 \\
\hline$>60$ & 3 & No response & 1 & & \\
\hline \multicolumn{6}{|c|}{ No response 2} \\
\hline * Denotes on-c & $\mathrm{cam}_{\mathrm{I}}$ & s location & & & \\
\hline
\end{tabular}




\begin{tabular}{|lll|}
\hline \multicolumn{3}{|c|}{ TABLE 2 } \\
Hourly Trends \\
\hline \hline Time & Fall & Spring \\
\hline 10 a.m.-1 p.m. & $23 \%$ & $23 \%$ \\
1 p.m.-5 p.m. & $42 \%$ & $47 \%$ \\
5 p.m.-12 a.m. & $35 \%$ & $30 \%$ \\
\hline
\end{tabular}

ing their IM shift. For evaluation purposes, the reported questions were grouped into several categories. The majority of questions received during IM reference fell into the information literacy $(26 \%)$ and catalog $(23 \%)$ categories. Information literacy questions required the librarian to explain the difference between the online catalog and electronic databases, to suggest a database, or to offer database search tips. The catalog category included questions about specific holdings or catalog terminology. As with exchanges at the physical reference desk, librarians found that many patrons do not understand the distinction between the Web-based catalog and electronic databases. Twelve percent of users required help navigating BISON Web pages and another 12 percent asked for specific library information such as hours, renewal policies, and so on. To a lesser extent, users requested assistance with technical troubleshooting $(6 \%)$, Web navigation $(5 \%)$, electronic course reserves $(4 \%)$, and finding UB information (4\%). Surprisingly, only five percent of users asked indepth questions about a particular subject while two percent posed short, factual questions (more had been expected). Another two percent sent inquiries about the library's IM service.

\section{Usage}

Based on data gathered from the system server, seventy-seven surveys were submitted in the fall and 185 in the spring. If one survey is interpreted to represent one reference interview, then between ten and eleven IM interviews per week were conducted in the fall, on average. In the spring, the rate grew to thirteen transactions per week, on average. Based on users' screen names, there were very few "repeat customers." To determine whether usage trends existed, the hours, days, and weeks were reviewed when surveys were submitted. These values reflect the time when the server received information, not necessarily when the user asked the question. It should be remembered that duplicate and incomplete entries as described earlier were eliminated and that not all patrons may have submitted a survey.

\section{Hourly Trends}

Table 2 shows that demand for IM service was greatest between 1 and 5 p.m. throughout the project. As for specific hours of use, survey submissions peaked during the 8 p.m. hour (14\%) in the fall and 2 p.m. (16\%) in the spring.

\section{Daily Trends}

As table 3 shows, daily use remained fairly consistent Monday through Thursday, declined on Friday and Saturday, and then increased on Sunday. To interpret the results correctly, it is important to consider that limited IM service was provided during Thanksgiving week. In the fall, more surveys were submitted on Tuesdays (20\%) than any other day, while in the spring Wednesday and Thursday led with 20 percent each.

\section{Weekly Trends}

Lastly, weekly trends were examined throughout the project. Figure 1 reveals that survey submissions increased gradually throughout the fall, excluding

\begin{tabular}{|lrr|}
\hline \multicolumn{3}{|c|}{ TABLE 3 } \\
Daily Trends in Survey \\
Submissions \\
\hline \hline Day & Fall & Spring \\
\hline Monday & $18 \%$ & $16 \%$ \\
Tuesday & $20 \%$ & $17 \%$ \\
Wednesday & $12 \%$ & $20 \%$ \\
Thursday & $16 \%$ & $20 \%$ \\
Friday & $9 \%$ & $10 \%$ \\
Saturday & $8 \%$ & $7 \%$ \\
Sunday & $16 \%$ & $11 \%$ \\
\hline
\end{tabular}




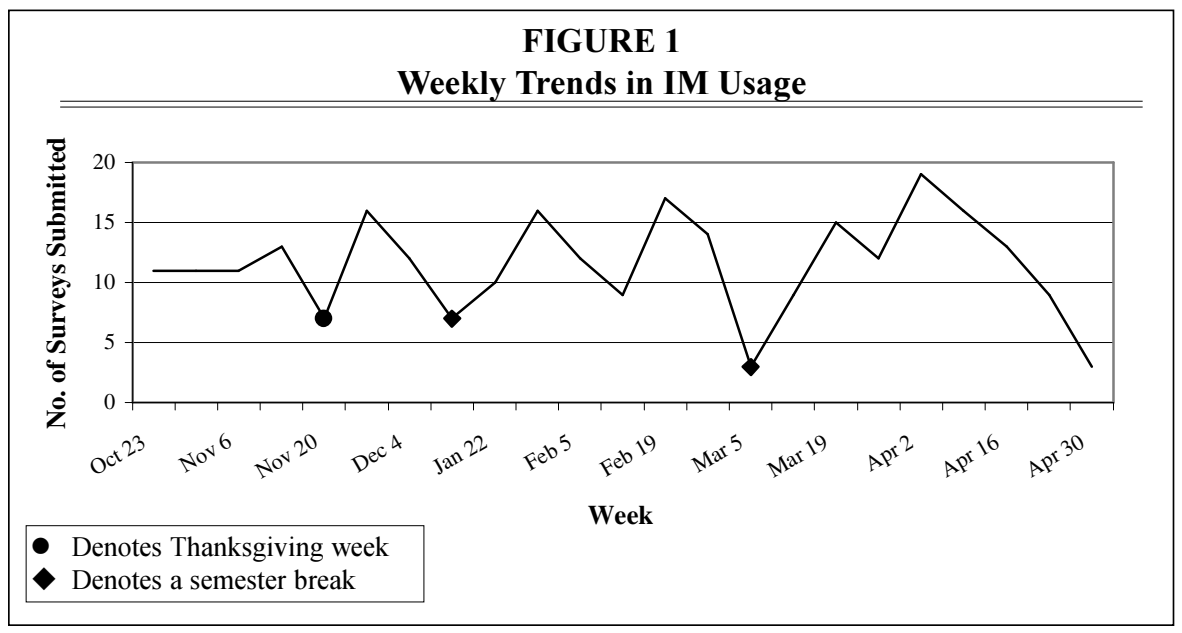

Thanksgiving week, and then tapered off during the last week of the semester. Spring showed no definitive patterns.

\section{Patron Comments}

The survey asked patrons why they chose to use IM versus calling, e-mailing, or visiting the library. Figure 2 presents a small sample of their responses. Overall, the comments were unexpectedly positive and very rewarding. Negative remarks typically came from visitors who tried to access the service when it was closed. One person remarked that the service should be made "more widely known." This underscores the lack of publicity and supports the criticism of library marketing that the users do not know what services are offered. ${ }^{8}$ Apparently, the Instant Message hyperlink confused a few people who thought it would open a generic chat session rather than take them to a specific library service.

\section{Librarians}

During the face-to-face meetings, it became evident that most librarians felt more pressure answering questions during IM than at a physical reference desk. They sensed an obligation to provide an exact answer and to provide it rapidly, making it difficult to give clear answers if the response required extensive typing. Much of this anxiety arose from serving online patrons who cannot exhibit facial expressions and body language for the librarian to interpret nor see the librarian actively working. However, these concerns may be misplaced because few users complained that a librarian took too much time. On the contrary, the majority of patrons were found to be patient, cordial, and very appreciative, particularly evening visitors.

Rarely were multiple patrons in the chat room at one time. When this did occur, the librarian worked with the first visitor and sent delay messages to the later arrivals. In fact, many librarians never received even one question, which led them to conclude that chat reference creates too much idle time for the on-duty librarian. Other librarians found it difficult to perform IM duty from their office because of a variety of workday distractions. A small number resented IM reference duty as an extra responsibility.

Punctual shift transitions proved to be the biggest staffing problem throughout the project. Although the shift schedule remained constant through the semester, librarians (not library students) frequently forgot their IM shift or arrived late because of other commitments. To improve shift coordination, the IM coordinator e-mailed reminders to librarians on the morning of their scheduled day. However, this effort met with little success, possibly because librarians frequently traded shifts without informing 


\section{FIGURE 2 \\ Patron Comments (Verbatim)}

\section{Responses to the survey question: Why did you choose IM versus calling,} e-mailing, or visiting the library?

working on paper... wanted instant help...

didn't want to leave my office and didn't feel like waiting on hold

I was off campus and the commute time is 40 minutes and it was easier to im the message than to make the commute. If I had called I would have had to locate the phone number and go through being transfered to someone who could help me if anyone knew who could help and then wait for them to become availaible. E-mailing would have taken just as long

because I thought it would be quicker, but nobody answered

it's more fun

It save time and it's convenient

Easy, fast and cool

Because it's cheaper to use the computers around campus than to call someone. I spend most of my time on my computer in my room, i guess that it's the same throughout school.

More direct dialect while being able to form my question by typing without being on the spot on the phone

because, i can still browsing while waiting for my answer =)

It was quicker then trying to find someone and there was no line to wait

Already sittiing at my computer - it's just a clik away....I think this is a really, really great idea and should be made more widely known that you can do this.

because i'm allready on the computer

immediacy!

I feel like I should know the answer.

most people i know are on AIM 24/7

I am out of state

It is easier and more convenient for an off campus student. I can't call if I am on the Internet, I only have one phone line.

Very convenient - quicker than e-mail, easier than telephone

because $i$ am a single mother, $i$ cannot just get up and go to the library whenever $i$ want, plus, i can't call if i'm on line..email takes too long. i need an answer now

the coordinator. Other staffing problems involved librarians using the wrong chat room and misunderstanding the difference between AIM and Express.

\section{Conclusions}

Evaluation of the IM reference pilot project revealed that the service achieved its goals. Statistics show that two of the target populations, young people and stu- dents in cybraries, used the service heavily. Although the majority of patrons were on-campus, comments indicated that the off-campus users included distance education students, another group the project had hoped to reach. Moreover, user comments demonstrated their enthusiasm and need for the IM reference.

Questions posed during chat reference were very similar to those received at the 
reference desk; primarily, they reflected patrons' confusion between the online catalog and electronic journals. Trend analyses suggest that most IM reference occurs in the afternoon and evening and remains fairly constant Monday through Thursday, with less traffic on Friday and Saturday. Weak promotional efforts prevented the library from drawing general conclusions about the effect of publicity.

Naming the real-time reference service with the ubiquitous term Instant Message caused unnecessary confusion among users. Perhaps one Web page that consolidates all electronic reference options would lessen perplexity and increase awareness. Titles devoid of librarian jargon also may help, for example, "Ask Us" or "Have a Question?" hours must be displayed prominently.
To alleviate many of the staffing problems encountered, the IM staff probably should remain small, receive more formalized training and extended practice, involve people with an interest in the virtual format, and perform shifts in a designated IM office (to remove distractions and facilitate shift transitions). To provide real-time reference service on a large scale, IM software should accommodate high volume, automate redundant tasks, compile statistics, and offer consistently reliable access.

The experiment with IM reference service may be considered a success, despite a few problems and some growing pains. Chat reference will not supplant the library's other reference services, but it offers another way to reach and educate patrons.

\section{Notes}

1. Marshall Breeding, "Providing Virtual Reference Service," Information Today (Apr. 2001): 42-43. Available online from <http:/ / www.infotoday.com>.

2. Carol Simpson, "INTERNET RESOURCES: Internet Relay Chat," Teacher Librarian 28, no. 1 (S 2000): 18-20. Available online for WilsonWeb subscribers from Library Literature \& Information Science FT, WilsonWeb <http: / /vweb.hwwilsonweb.com>. (1 June 2001).

3. Phil Blank, "Live On Line Reference," Duke University Libraries. 14 December 2000. Available online from <http:/ / www.lib.duke.edu/reference/liveonlineref.htm>. (5 April 2001).

4. Gloria Colvin, "Remote, Accessible, and On Call: Reference Librarians Go Live," Florida Libraries 44, no. 1 (spring 2001): 10-12. Available online for WilsonWeb subscribers from Library Literature \& Information Science FT, WilsonWeb <http: / /vweb.hwwilsonweb.com>. (1 June 2001).

5. Blank, "Live On Line Reference."

6. Rob Bernstein, Jeremy Caplan, and Eric Glover, "America's 100 Most Wired Colleges 2000," Yahoo! Internet Life (May 2000). Available online from <http:/ / www.zdnet.com/yil/content/college/college2000/rank_university_100.html>. (9 June 2001).

7. Simpson, "INTERNET RESOURCES: Internet Relay Chat."

8. Sara Weissman, "Know Your Audience," Library Journal Net Connect (spring 2001): 42. Available online for WilsonWeb subscribers from Library Literature \& Information Science FT, WilsonWeb <http:/ /vweb.hwwilsonweb.com>. (1 June 2001).

9. Ibid. 